\title{
A novel variant of KCNQ1 gene and pathogenicity prediction in a family with long QT syndrome type 1
}

\author{
Jian Song ${ }^{1}$, Guoming $\mathrm{Chu}^{1}$, and Pingping $\mathrm{Li}^{1}$ \\ ${ }^{1}$ Shengjing Hospital of China Medical University
}

February 20, 2022

\begin{abstract}
We report a novel heterozygous missense variant of $K C N Q 1$ in a family exhibiting LQTS with complete penetrance and predict its pathogenicity through multiple prediction software programs and 3D model analysis. Whole-exome sequencing (WES) was performed in a family with symptoms of LQTS. The pathogenicity of the identified variant was predicted for its effect on a 3D model of KCNQ1, and in-depth functional analysis was performed for mechanistic speculation. A novel heterozygous variation c.716T $>\mathrm{G}$ in $K C N Q 1$ with autosomal dominant inheritance was identified. We demonstrated that this variant, which is located in the conserved hot spot domain, was evaluated as likely pathogenic. In silico prediction indicated that the variation was involved in the process of channel closing/opening. This study reports a novel variation in $K C N Q 1$, provides supportive evidence for pathogenicity prediction and enhances variant interpretation for patients with LQTS.
\end{abstract}

\section{Hosted file}

manuscript.docx available at https://authorea.com/users/461404/articles/557107-a-novelvariant-of-kcnq1-gene-and-pathogenicity-prediction-in-a-family-with-long-qt-syndrometype-1 
A

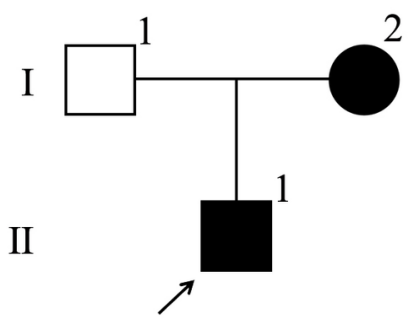

C

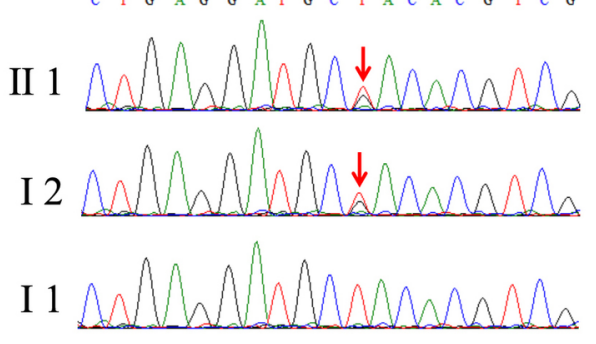

B

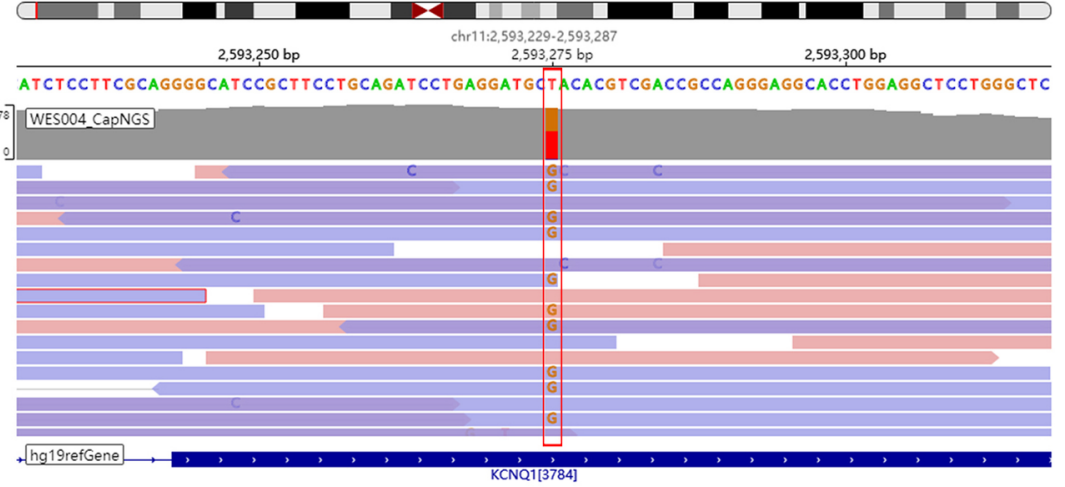

A
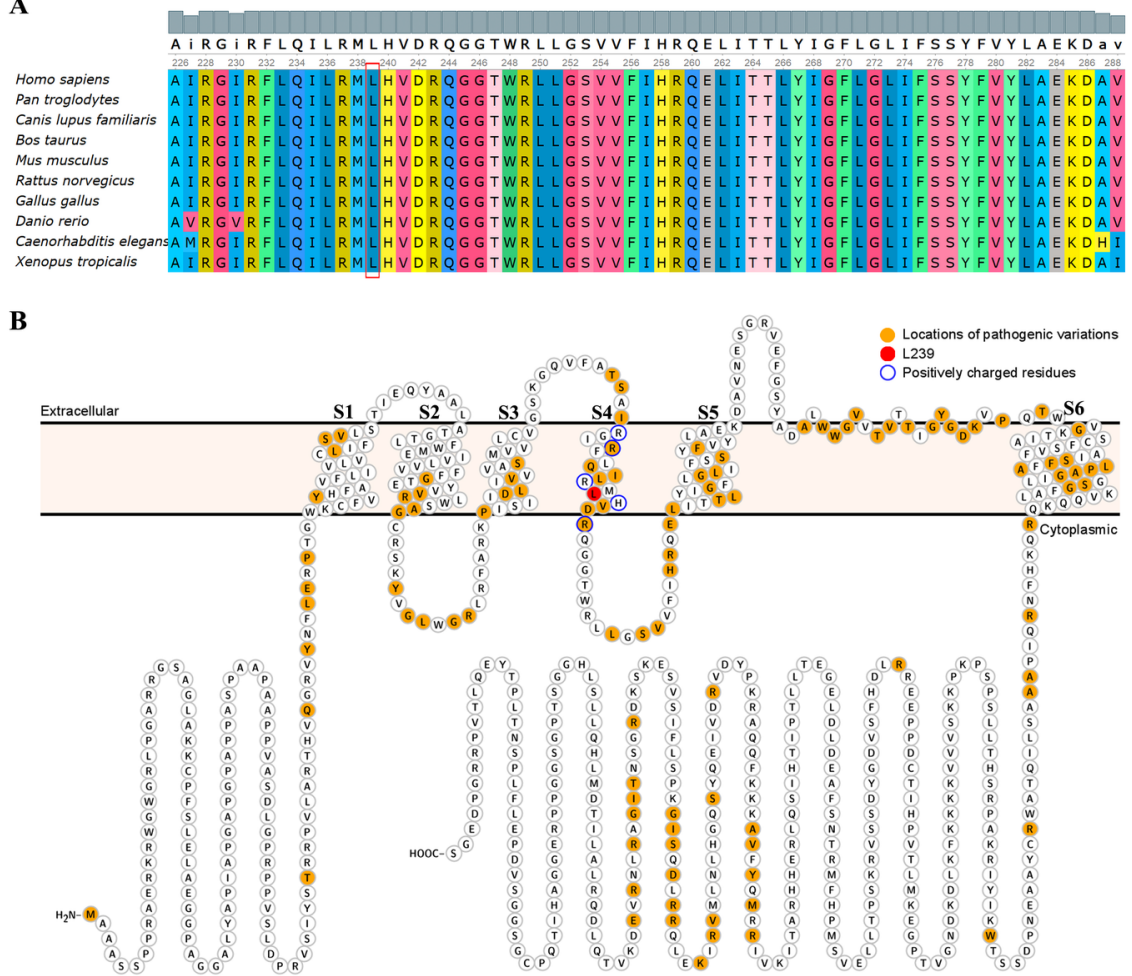

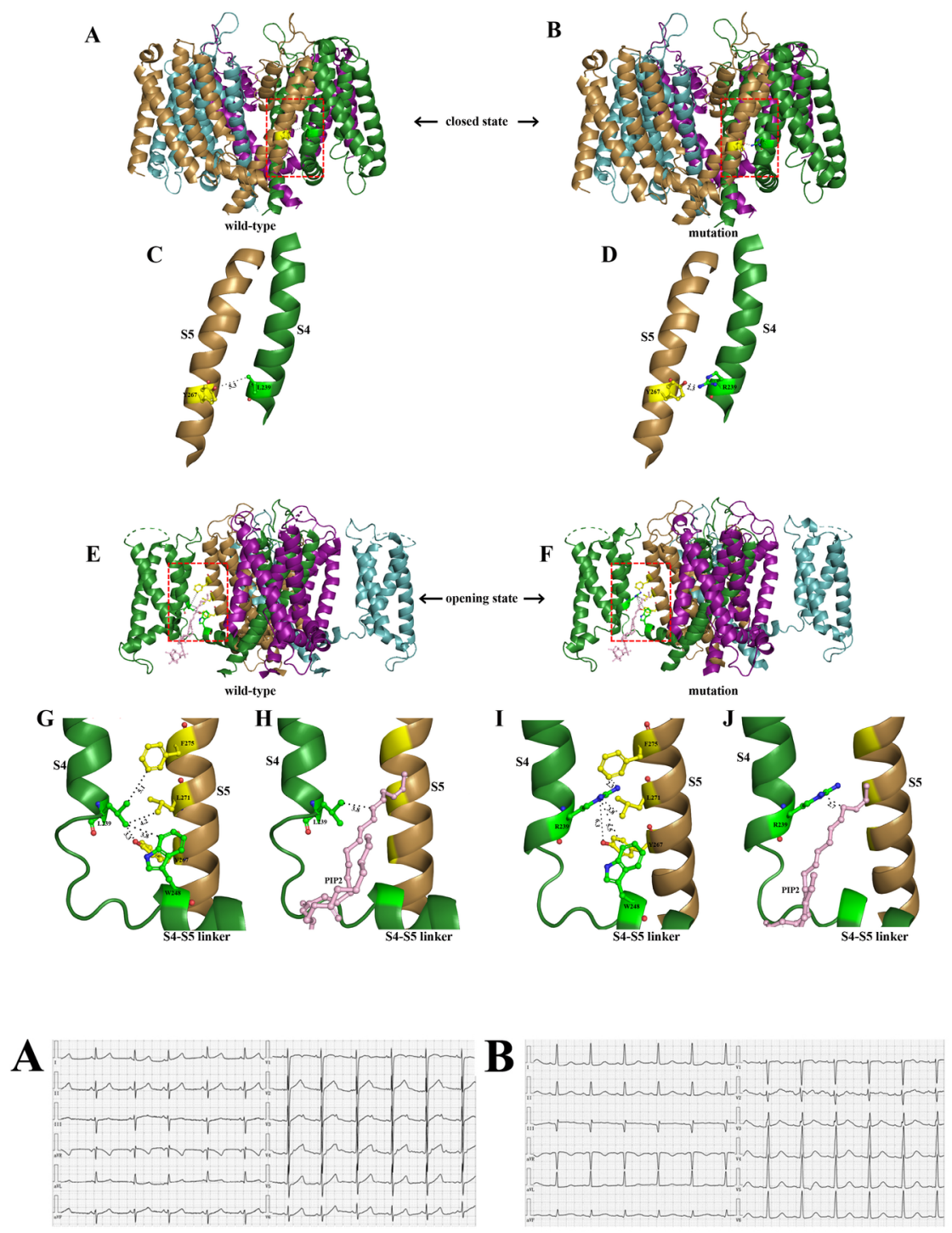

\section{Hosted file}

Table 1.docx available at https://authorea.com/users/461404/articles/557107-a-novel-variantof-kcnq1-gene-and-pathogenicity-prediction-in-a-family-with-long-qt-syndrome-type-1 